\title{
Anostracan monopolisation of early successional phases in temporary waters?
}

\author{
M. Jocque ${ }^{1,2}$, B. Vanschoenwinkel ${ }^{1}$ and L. Brendonck ${ }^{1}$
}

With 1 figure and 1 table

\begin{abstract}
The length of the hydrocycle restrains the development of communities in temporary aquatic habitats. Little information is available on the importance of biotic interactions in shaping the communities in these habitats. A common observation in the freshwater rock pool community assembly process is the clearly separated density peaks of fairy shrimp (Anostraca) and cladocerans (Anomopoda) over time. Fairy shrimp (Anostraca), the flagship group and dominant filter feeders of temporary waters hatch early after inundation. This contrasts with the occurrence pattern of coexisting cladocerans, which despite higher chances of abortive hatching occur later during the hydroperiod. To study this apparent succession pattern and test the possible presence of a biotic interaction, we set up enclosure experiments in freshwater rock pools in Western Australia and monitored cladoceran (Macrothrix hardingii) densities in the presence of variable densities or absence of fairy shrimp (Branchinella longirostris). The anomopod cladoceran populations decreased with increasing anostracan densities revealing a negative biotic interaction. The competitive dominance of anostracans most probably was mainly due to exploitation competition, with possibly elements of interference competition or predation included. Early hatching and competitive superiority may help anostracans in temporary pools to monopolize the habitat with respect to small and/or other filter feeding invertebrates. As such they influence succession dynamics and invertebrate community structure, making anostracans keystone species of temporary pools.
\end{abstract}

Key words: Anostraca, Cladocera, competition, rock pool, succession

\section{Introduction}

Species rarely occupy their entire fundamental niche as determined by their tolerance limits. Biotic interactions, of which competition and predation are probably the most important (Kerfoot \& Sih 1987), restrict species to only a fraction of their total niche (i.e. the realized niche; Putman 1995). The presence and strength of biotic interactions depends on the complexity of the food web and the overlap in niche space of the component species.

Inhabitants of temporary aquatic habitats are frequently exposed to a stressful abiotic environment, es- pecially as the habitat disappears once or several times a year due to evaporation or freezing. The particular adaptations required to persist in such temporary habitats strongly limit the number of species persisting in this environment. If the inundation period increases, less specific adaptations are needed for survival and in general an increase in species richness is expected. Along with species richness, the complexity of the food web and the intensity of species interactions in a community increases (Wiggins et al. 1980, Wellborn 1996, Urban 2004). The relevance of biotic interactions in temporary waters as structuring factors of communities is only fragmentarily understood. Exam-

\section{Authors' address:}

${ }^{1}$ K. U. Leuven, Laboratory of Aquatic Ecology and Evolutionary Biology, Charles Debériotstraat 32, 3000 Leuven, Belgium.

${ }^{2}$ Corresponding author, present address: Central Laboratory of General Ecology, Bulgarian Academy of Sciences, 2 Yurii Gagarin Street, 1113 Sofia, Bulgaria.

e-mail:MerlijnJocque@gmail.com 
ples include competition and parasitism in cladocerans (Bengtsson 1989, Bengtsson 1993, Bengtsson \& Ebert 1998), competition in Corixidae (Pajunen 1979a, Pajunen 1979b, Pajunen \& Pajunen 1993) and predation on Anostraca (Brendonck et al. 2002, De Roeck et al. 2005). Blaustein et al. (1995) showed the potential consequences of predation pressure for distribution patterns of entire invertebrate communities. Considering the limited time available in some temporary habitats, biotic interactions are in most cases not expected to reach equilibrium or lead to the exclusion of interacting taxa (Bengtsson 1986). It is therefore expected that they contribute only minimally to community structure.

In a study of invertebrate community succession in temporary freshwater rock pools in Botswana, distinct population density peaks of Anostraca (Branchipodopsis wolfi Daday 1910) and Cladocera (Leberis sp.) were observed in the same pool, where the cladocerans took over when the last anostracan died off (Jocque et al. 2007). Similar patterns were observed in temporary rock pools in South Africa (Vanschoenwinkel, pers. observ.) and Western Australia (Jocque, pers. observ.). Early hatching triggered by ecologically informative cues, combined with a bet-hedging strategy, is a major adaptation to persist in unpredictable temporary aquatic habitats (Simovich \& Hathaway 1997, Brendonck et al. 2000, Brendonck \& Riddoch 2001). The late density peak of the cladocerans compared to the anostracans does not seem to be a beneficial strategy in ephemeral habitats and may be an indication for a negative biotic interaction between those two taxa.
On the other hand, the delayed presence of cladocerans might also result from other independent factors such as a differential sensitivity to predation pressure, which usually increases during inundations (Spencer et al. 1999), or a differential population build up. The late presence of Cladocera could possibly also result from a delayed hatching due to environmental clues indicating the presence of predators as was suggested by the lower hatching of Ceriodaphnia quadrangular Müller in the presence of salamander larvae (Blaustein 1997). Anostraca, the flagship group of permanent inhabitants in temporary waters (Belk 1998), are among the first organisms that hatch in newly inundated habitats (e.g. Lahr et al. 1999), this may contrast with the slower population build up of cladocerans.

In this study, we explicitly test the hypothesis that the commonly observed late density peak of cladocerans in temporary waters is due to a negative interaction with fairy shrimp, which are usually abundant in early stages of the hydroperiod. We monitored densities of an anomopodan population (Macrothrix hardingi) over time exposed to variable Anostraca densities in enclosures placed in freshwater rock pools on top of an inselberg in West Australia.

\section{Material and methods}

We tested for a relationship between population densities of Branchinella longirostris (Wolf 1911) (Branchiopoda: Anostraca) and Macrothrix hardingi Petkovski 1973 (Branchiopoda: Cladocera: Anomopoda) in rock pools using field enclosures. The experiments were conducted on Wave rock, a granite out-

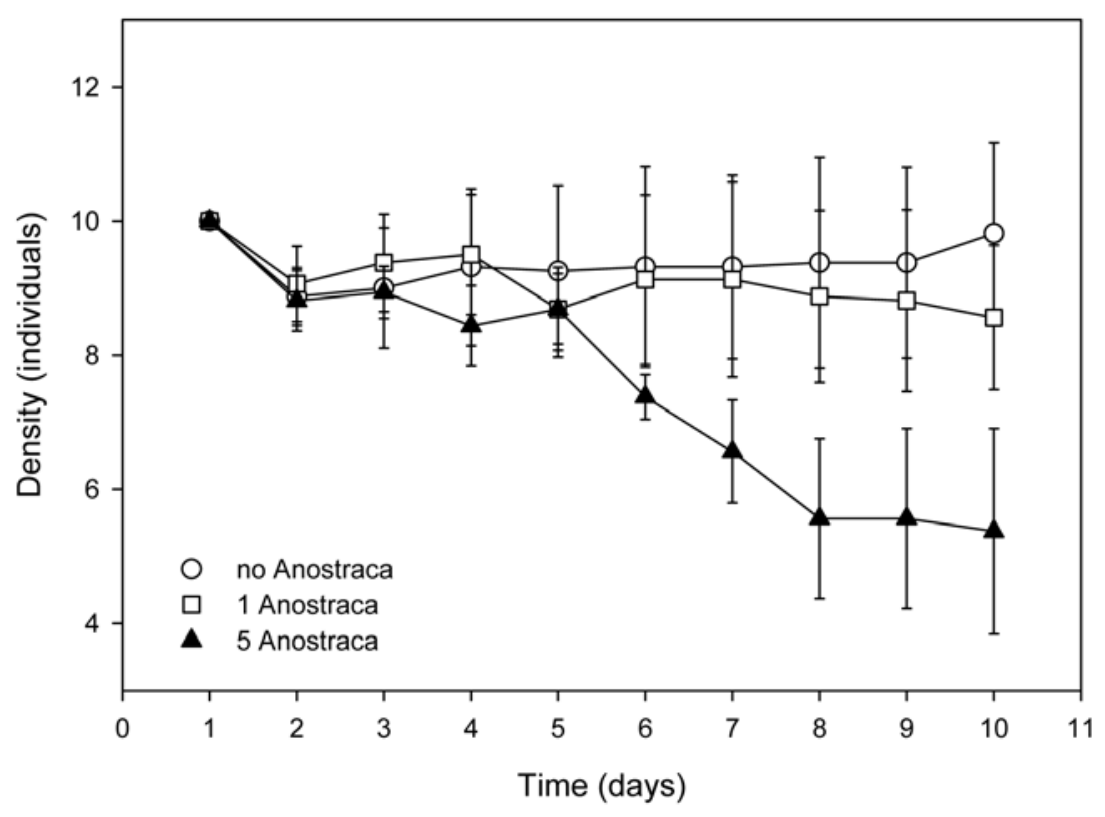

Fig. 1. Cladocera (Macrothrix hardingii) density dynamics over time in the presence of none, one or five Anostraca (Branchinella longirostris), averaged over all replicates in the four pools $( \pm 1$ standard error). 
crop near Hyden, Western Australia. Four medium sized pools (roughly $4 \mathrm{~m}^{2}$ surface and less than $20 \mathrm{~cm}$ maximum depth) were randomly selected. In each pool four clusters (replicates) each of three enclosures (treatments) were placed according to a randomized block design, resulting in 48 enclosures in total. Enclosures consisted of plastic $200 \mathrm{ml}$ containers with a $64 \mu \mathrm{m}$ bottom mesh. When placed in the pools they contained between 150 and $175 \mathrm{ml}$ of water. At the beginning of the experiment every enclosure was inoculated with ten cladocerans from the pool holding the respective enclosures. The inoculated number of cladocerans equalled the average natural density at that moment in the respective four pools. Three densities of Anostraca were then added; zero (the control), one (low-density treatment) and five individuals (high-density treatment). Although $B$. longirostris naturally occurs on Wave Rock, the pools had been inundated for a substantial time already ( $>2$ months, Timms, pers. comm.) and advanced in the hydroperiod. Therefore, no Anostraca were present in the pools at the moment the experiment was conducted. The anostracans used in the experiment were therefore collected from a nearby $(50 \mathrm{~km}$ North East of Hyden) granite outcrop called "the humps". After initiation of the experiment, cladoceran densities were recorded every day between 9.00-11.00 a.m. for 10 days. Dead anostracans were replaced.

\section{Statistical analysis}

Differences in cladoceran densities (number of individuals per enclosure) under the different treatments were analyzed with a repeated measures analysis. The sequential nature of the data with a chance that measurements taken more closely in time are also more strongly correlated, may, however, result in less accurate analyses by traditional forms of ANOVA (Keselman et al. 1999). We therefore used a general linear mixed model (Proc MIXED in SAS/STAT 8.0) and an autoregressive covariance structure (AR1) that was selected based on AIC (Burnham \& Anderson 1998). The nested structure of our design (four replicas per treatment nested in four pools) was explicitly taken into account by including POOL as a factor in our model. We tested for significant differences between treatments using post hoc tests (CONTRAST statement) providing F-statistics. Corresponding P-values were Bonferroni corrected for table wide errors.

\section{Results}

Figure 1 presents the dynamics of cladoceran densities in the enclosures. We found significant effects of the treatments (Table 1) as well as a significant time $\times$ treatment interaction. Cladoceran densities decreased significantly over time in the presence of Anostraca and remained constant in the control. Post hoc tests revealed significant differences between the control and the high anostracan density treatment $(F=7.98$; $\mathrm{P}=0.0055)$, and between the low and the high anostracan density treatment $(\mathrm{F}=7.75 ; \mathrm{P}=0.0067)$, but not between the control and the low anostracan density treatment $(\mathrm{F}=0.02 ; \mathrm{P}=0.9)$.
Table 1. Results of the General Linear Model (GLM), testing for effects of competition treatment, time, treatment - time interaction and individual pool on cladoceran density.

\begin{tabular}{lrll}
\hline Model: cladoceran density & Df & F-value & P \\
Treatment & 2 & 5.13 & 0.0075 \\
Time & 8 & 2.00 & 0.046 \\
Time $\times$ treatment & 16 & 1.83 & 0.026 \\
Pool & 3 & 8.15 & 0.0003 \\
\hline
\end{tabular}

Cladoceran densities in all three treatments stabilized during the experiment. Both the control and the treatment with one fairy shrimp stabilized after two days, while cladoceran populations in the presence of five fairy shrimps stabilized after eight days (Fig. 1). We also observed significant differences between pools (Table 1).

\section{Discussion}

Cladoceran (Macrothrix hardingii) densities decreased in the presence of Anostraca (Branchinella longirostris) in all enclosures. With the size of the start-up population of cladocerans in the enclosure experiment based on counts of natural densities in anostracan-free pools at the moment of the study, our results suggest that the observed cladoceran densities probably would not have been reached in the presence of high densities of $B$. longirostris. The observed negative interaction between these two branchiopod taxa in the rock pools provides a possible explanation for the observed temporal segregation in population peak density of these taxa (Jocque et al. 2007). The dominance of Anostraca over cladocerans in certain types of temporary pools is most probably rooted in adaptations of Anostraca to the ephemeral and unpredictable aspects of these habitats. The major stress factor for temporary pool inhabitants is early drought of the pool (Batzer \& Wissinger 1996). Early hatching combined with a fast growth is crucial in the race to mature and reproduce in time (Brendonck et al. 2000, Brendonck \& Riddoch 2001). In combination with early recolonization we believe that due to a very efficient filtering system, fairy shrimp effectively monopolize resources immediately after the flooding of a pool, yielding a strong priority effect (De Meester et al. 2002). In the generally oligotrophic rock pools, this does not leave much room for later arriving and/or less efficient filter feeders.

Fast growth is based on an efficient collection of large quantity of and/or good quality food. In general Anostraca may be described as efficient free-swim- 
ming filter feeders (Dodson \& Frey 2001). One individual filters about 1 litre per hour (Dumont \& Ali 2004). Anostraca are expected to be more efficient filter feeders than cladocerans due to their larger size resulting in the ability to filter a larger size spectrum of particles and a larger amount of water (Brendonck 1993a) compared to the smaller cladocerans with less filtering limbs.

Anostraca are omnivores. Brendonck et al. (2000) mention the flexible feeding behaviour of Branchipodopsis wolfi helping to survive in the nutrient poor conditions of diluted rock pools. Anostraca consume a wide variety of organic particles, such as phytoplankton and bacteria (Brendonck 1993a,b, Dierckens et al. 1997) and are also known to ingest rotifers (Starkweather 2005), nematodes, cladocerans (Bernice 1971) and other small invertebrates (Mertens et al. 1990). Some large anostracans even actively hunt and predate on other organisms (Fryer 1966, White et al. 1969, Rogers et al. 2006). The omnivory of Anostraca allows them to utilize a wide range of food types, providing the necessary flexibility to survive in these nutrient poor habitats. In addition, the ingestion of nauplii and other larval stages of other species may help eliminate potential competitors. The observed negative interaction between fairy shrimp and cladocerans in our experiment could be complemented by a predatory effect via consumption or disturbance of juvenile cladoceran stages. Dumont \& Ali (2004) report that Streptocephalus proboscideus (Frauenfeld 1873) individuals cannibalize their own nauplii, creating a self-regulating control of population density, with the adults consuming the newly hatched nauplii. Based on this observation, it can be expected that other small crustaceans or their offspring could also serve as food source. However, if there would be a strong predatory element between Anostraca and cladocerans in our experiment, we would expect decimation of the cladoceran populations in less than a day based on the filtering rates of Streptocephalus proboscideus (Mertens et al. 1990). This is not the case. Even in the highest density treatment with five Anostraca, cladoceran densities stabilized to approximately six individuals for the last three days of the experiment (Fig. 1). Cladoceran communities reached carrying capacity indicating that interference competition or predation was most probably not very important.

Due to the combination of competitive dominance, possibly reinforced with interference competition and/ or predation, fairy shrimp may be able to outcompete cladocerans and other filter feeders. However, due to their large size and active behavior, Anostraca are particularly vulnerable to predation, mostly by insect predators (Brendonck et al. 2002), but also by some amphibians (Wissinger et al. 1999) and turbellarians (Dumont \& Schorreels 1990, De Roeck et al. 2005). These usually become abundant later on during inundations and are reported to quickly decimate anostracan populations. A drop in Anostraca densities during inundations caused by increased predation risk may help cladocerans and other small and /or filter feeding organisms to fully develop their populations. From this point of view by monopolizing the first successive phase of a temporary pool, fairy shrimp may have a considerable effect on community structure. Fairy shrimp may therefore not only be considered flagship species but also keystone species of this habitat type.

Our results follow the seasonal change in zooplankton community structure with turn over of large-bodied (e.g. Daphnia sp.) by smaller bodied species (e.g. Ceriodaphnia sp.) that is documented for large standing waters (Sommer et al. 1986). The size-efficiency hypothesis, stating that large bodied zooplankton species are competitively superior to small-bodied ones, is often used to explain this shift. Large species are competitively superior and occur in the beginning of the season, until size-selective predation on large zooplankton by planktivores shifts dominance to smaller forms (Gliwicz \& Pijanowska 1989). Also other elements such as resource quality and variability in presence, temperature, and productivity of a habitat have all been cited as factors that can influence zooplankton community structure, as well as the strength and outcome of competitive interactions between large and small-bodied taxa (e.g. Bengtsson 1986). The extreme differences in size and high vulnerability of the Anostraca to predation suggest that this most probably will be the main driving factor explaining the successional shift from Anostraca to cladocerans. We observed that the competition interactions are not static but highly dynamic, varying both spatially (between pools) and temporally. This variation between pools can be related with the nutritional quality of resources (Steiner 2003), or other variability in the abiotic or biotic environment. The influence of environmental variability between pools on biotic interactions can be substantial as was observed by Sanchez \& Angeler (2007) during a set up of enclosures to test the influence of Branchinecta orientalis Sars 1901 on zooplankton communities. Here, the high degree of environmental variability between pools compromised the detection of any influence of fairy shrimps on zooplankton community structure (Sanchez \& Angeler 2007). 


\section{Conclusions}

The appearance and success of cladocerans in temporary pools during late inundation phases of temporary pools is at least partly caused by a competitive dominance of Anostraca. We expect a certain degree of interference competition; disturbing and stressing the water fleas, which may further reinforce the direct competitive advantages of the Anostraca (efficient filter feeding), complemented by possible predation on cladoceran neonates. Future experiments, however, are needed to elucidate the fine scale mechanism of this interaction. Considering different development stages of other temporary pool organisms may help to increase our understanding of the general success and dominance of Anostraca in ephemeral water bodies.

\section{Acknowledgements}

We thank David Angeler, Anne Robertson and an anonymous reviewer for suggestions to improve the manuscript. M. Jocqué is supported by an IWT (Institute for the Promotion of Innovation by Science and Technology in Flanders) PhD scholarship. Bram Vanschoenwinkel is supported by the Fund for scientific research Flanders (FWO). This research is financially supported by project G.0118.03 of the FWO (Fund for Scientific Research in Flanders). We would like to thank Brian Timms for providing accommodation for two months and an exquisite support in the field.

\section{References}

Batzer, D. P. \& Wissinger, S. A., 1996: Ecology of insect communities in non-tidal wetlands. - Ann. Rev. Ent. 41: 75100.

Belk, D., 1998: Global status and trends in ephemeral pool invertebrate conservation: implications for Californian fairy shrimp. - In: Withman, C. W., Bouder, E., Belk, D., Ferrer, W. \& Ornduff, R. (eds): Ecology, Conservation and Management of vernal pool ecosystems. - Proceedings from a 6 Conference. California native plant society. Sacramento, USA.

Bengtsson, J., 1986: Life histories and interspecific competition between three Daphnia species in rock pools. - J. Anim. Ecol. 55: 641-655.

Bengtsson, J., 1989: Interspecific competition increases local extinction rate in a metapopulation system. - Nature 340: 713-715.

Bengtsson, J., 1993: Interspecific competition and determinants of extinction in experimental populations of three rock pool Daphnia species. - Oikos 67: 451-464.

Bengtsson, J. \& Ebert, D., 1998: Distributions and impacts of microparasites on Daphnia in a rock pool metapopulation. Oecologia 115: 213-221.

Bernice, R., 1971: Food, feeding and digestion in Streptocephalus dichotomus Baird (Crustacea: Anostraca). - Hydrobiologia 38: 507-520.

Blaustein, L., 1997: Non-consumptive effects of larval Salamandra on crustacean prey: can eggs detect predators? Oecologia 110: 212-217.
Blaustein, L., Kotler, B. P. \& Ward, D., 1995: Direct and indirect effects of a predatory backswimmer (Notonecta maculata) on community structure of desert temporary pools. Ecol. Entomol. 20: 311-318.

Brendonck, L., 1993a: Feeding in the fairy shrimp Streptocephalus proboscideus (Frauenfeld) (Branchiopoda: Anostraca). I. Aspects of the feeding biology. - J. Crust. Biol. 13: 235-244.

Brendonck, L., 1993b: Feeding in the fairy shrimp Streptocephalus proboscideus (Frauenfeld) (Branchiopoda: Anostraca). II. Influence of environmental conditions on feeding rate. - J. Crust. Biol. 13: 245-255.

Brendonck, L., Hamer, M. L., Riddoch, B. J. \& Seaman, M. T., 2000: Branchipodopsis species - specialists of ephemeral rock pools. - Afr. J. Aquat. Sci. 25: 98-104.

Brendonck, L., Michels, E., De Meester, L. \& Riddoch, B. J., 2002: Temporary pools are not enemy free. - Hydrobiologia 486: $147-159$.

Brendonck, L. \& Riddoch, B. J., 2001: Hatching characteristics of the fairy shrimp Branchipodopsis wolfi in relation to the stochastic nature of its habitat, desert rock pools. - Verh. Internat. Verein. Limnol. 27: 3931-3935.

Burnham, K. P. \& Anderson, D. R., 1998: Model selection and inference: a practical information-theoretic approach. Springer-Verlag, New York, USA.

De Meester, L., Gomez, A., Okamura, B. \& Schwenk, K., 2002: The monopolization hypothesis and the dispersal-gene flow paradox in aquatic organisms. - Acta Oecol. 23:: 121-135.

De Roeck, E. R. M., Artois, T. \& Brendonck, L., 2005: Consumptive and non-consumptive effects of turbellarian (Mesostoma sp.) predation on anostracans. - Hydrobiologia 542: 103-111.

Dierckens, K. R., Beladjal, L., Vandenberghe, J., Swings, J. \& Mertens, J., 1997: Filter-feeding shrimps (Anostraca) grazing on bacteria. - J. Crust. Biol. 17: 264-268.

Dodson, S. I. \& Frey, D. G., 2001: The Cladocera and other Branchiopoda. - In: Thorpe, J. E. \& Covich, A. P. (eds): Ecology and systematics of North American freshwater invertebrates. $2^{\text {nd }}$ Edition. - Academic Press, San Diego, USA.

Dumont, H. J. \& Ali, A. J., 2004: Stage-specific cannibalism and spontaneous cyst hatching in the freshwater fairy shrimp Streptocephalus proboscideus Frauenfeld. - Hydrobiologia 524: 103-113.

Dumont, H. J. \& Schorreels, S., 1990: A laboratory study of the feeding of Mesostoma lingua (Schmidt) (Turbellaria, Neorhabdocoela) on Daphnia magna Straus at 4 different temperatures. - Hydrobiologia 198: 79-89.

Fryer, G., 1966: Branchinecta gigas Lynch, a non-filter-feeding raptatory anostracan, with notes on the feeding habits of certain other anostracans. - Proc. Linn. Soc. London 177: 19-34.

Gliwicz, Z. M. \& Pijanowska, J., 1989: The role of predation in zooplankton succession. - In: Sommer, U. Z. (ed.): Plankton ecology. - Springer-Verlag, New York, USA.

Jocque, M., Riddoch, B. J. \& Brendonck, L., 2007: Successive phases and species replacements in freshwater rock pools with a biological definition of ephemeral water bodies. Freshwat. Biol. 52: 1734-1744.

Kerfoot, W. C. \& Sih, A., 1987: Predation: Direct and indirect impacts on aquatic communities. - University Press of New England, New Hampshire, U. S.A. 
Keselman, H. J., Algina, J., Kowalchuk, R. K. \& Wolfinger, R. D., 1999: A comparison of recent approaches to the analysis of repeated measurements. - Br. J. Math. Stat. Psychol. 52: 63-78.

Lahr, J., Diallo, A. O., Ndour, K. B., Badji, A. \& Diouf, P. S., 1999: Phenology of invertebrates living in a Sahelian temporary pond. - Hydrobiologia 405: 189-205.

Mertens, J., Munuswamy, N., Dewalsche, C. \& Dumont, H. J., 1990: On predatory tendencies in the feeding ecology of the fairy shrimp Streptocephalus proboscideus (Frauenfeld, 1873) (Crustacea, Anostraca). - Hydrobiologia 198: 119-123.

Pajunen, V. I., 1979a: Quantitative analysis of competition between Arctocorisa carinata (Sahlb.) and Callicorixa producta (Reut.) (Hemiptera, Corixidae). - Annal. Zool. Fenn. 16: 195-200.

Pajunen, V. I., 1979b: Competition between rock pool corixids. - Annal. Zool. Fenn. 16: 138-143.

Pajunen, V. I. \& Pajunen, I., 1993: Competitive interactions limiting the number of species in rock pools: experiments with Sigara nigrolineata. - Oecologia 95: 220-225.

Putman, R. J., 1995: Community Ecology. - Chapman \& Hall, London. England.

Rogers, D. C., Quinney, D. L., Weaver, J. \& Olesen, J., 2006: A new giant species of predatory fairy shrimp from Idaho, USA (branchiopoda : anostraca). - J. Crust. Biol. 26: 1-12.

SAS Institute Inc., 2003: SAS (data analysis software system), version 9. www.SAS.com.

Sanchez, B. \& Angeler, D. C., 2007: Can fairy shrimp (Anostraca: Crustacea) structure zooplankton communities in temporary ponds? - Mar. Freshwat. Res. 58: 827-834.

Simovich, M. A. \& Hathaway, S. A., 1997: Diversified bethedging as a reproductive strategy of some ephemeral pool anostracans (Branchiopoda). - J. Crust. Biol. 17: 38-44.
Sommer, U., Gliwicz, M., Lampert, W. \& Duncan, A., 1986: The PEG-model of seasonal succession of planktonic events in freshwaters. - Arch. Hydrobiol. 106: 433-471.

Spencer, M., Blaustein, L., Schwartz, S. S. \& Cohen, J. E., 1999: Species richness and the proportion of predatory animal species in temporary freshwater pools: relationships with habitat size and permanence. - Ecol. Lett. 2: 157-166.

Starkweather, P. L., 2005: Susceptibility of ephemeral pool Hexarthra to predation by the fairy shrimp Branchinecta mackini: can predation drive local extinction? - Hydrobiologia 546: 503-508.

Steiner, C. F., 2003: Variable dominance in pond communities: assessing spatiotemporal variation in competition and predation intensity. - Ecology 84: 982-990.

Urban, M. C., 2004: Disturbance heterogeneity determines freshwater metacommunity structure. - Ecology 85: 29712978.

White, B., Fabris, G. \& Hartland-Rowe, R., 1969: The method of prey capture by Branchinecta gigas Lynch, 1937 (Anostraca). - Crustaceana 16: 158-160.

Wellborn, G. A., Skelly, D. K. \& Werner, E. E., 1996: Mechanisms creating community structure across a freshwater habitat gradient. - Annu. Rev. Ecol. Syst. 27: 337-363.

Wiggins, G. B., Mackay, R. J. \& Smith, I. M., 1980: Evolutionary and ecological strategies of animals in annual temporary pools. - Arch. Hydrobiol. 58: 97-206.

Wissinger, S. A., Bohonak, A. J., Whiteman, H. H. \& Brown, W. S., 1999: Subalpine wetlands in Colorado: Habitat permanence, salamander predation and invertebrate communities. - In: Bazter, D. P. \& Wissinger, S. A. (eds): Invertebrates in freshwater wetlands of North America: ecology and management. - John Wiley \& Sons. New York. USA. 